\title{
КОМПЬЮТЕРНАЯ ОЦЕНКА НЕБЛАГОПРИЯТНЫХ ЭФФЕКТОВ МЕЖЛЕКАРСТВЕННЫХ ВЗАИМОДЕЙСТВИЙ НА СЕРДЕЧНО-СОСУДИСТУЮ СИСТЕМУ
}

\author{
В.С. Сухачёв, С.М. Иванов, Д.А. Филимонов, В.В. Поройков \\ Лаборатория структурно-функционального конструирования лекарств, \\ ФГБНУ НИИ биомедицинской химии им. В.Н. Ореховича, \\ 119121, Россия, г. Москва, Погодинская ул., д. 10, стр. 8.
}

DOI: 10.19163/MedChemRussia2021-2021-180

E-mail:withstanding@yandex.ru

Совместное применение лекарственных средств часто приводит к межлекарственным взаимодействиям, которые могут сопровождаться различными неблагоприятными эффектами, представляющими угрозу для жизни и здоровья пациентов. Неблагоприятное воздействие на сердечно-сосудистую систему является одним из наиболее значимых эффектов межлекарственных взаимодействий. Клиническая оценка неблагоприятных эффектов взаимодействий между всеми использующимися в терапевтической практике парами лекарств не представляется возможной.

Цель данной работы заключалась в построении моделей для прогнозирования неблагоприятных эффектов взаимодействий пар лекарств на сердечно-сосудистую систему с применением анализа «структура-активность».

Данные о неблагоприятных эффектах взаимодействий 1300000 уникальных пар лекарств были получены из базы данных DrugBank ${ }^{1}$. Для описания пары структур лекарств были использованы PoSMNA дескрипторы². Модели были построены при помощи модифицированного наивного байесовского классификатора, реализованного в программе PASS 3,4 . Средняя точность прогноза сердечно-сосудистых эффектов, вычисленная на основе скользящего контроля с исключением по одному, превысила $80 \%$. Точность прогноза составила 72\% для аритмии, 90\% для брахикардии, 74\% для удлинения интервала QT на ЭКГ, 86\% для тахикардии, 87\% для гипертензии и 72\% для гипотензии.

Полученные результаты позволяют прийти к заключению о применимости методов анализа «структура-активность» для прогнозирования неблагоприятных эффектов межлекарственных взаимодействий.

Исследование выполнено при поддержке Российского научного фонда

(проект № 17-75-20250).

\section{Литература}

[1] https://go.drugbank.com

[2] A. Dmitriev et. al, Pharmaceutics. 2021, 13(4), 538

[3] D. Filimonov et al., Chemistry of Heterocyclic Compounds. 2014, 50(3), 444-457

[4] http://www.way2drug.com/PASSOnline 